\title{
Researches on Application Fields of 3D Printing Technology in Product Design and Production*
}

\author{
Haijiao Sun \\ Zhuhai College of Jilin University \\ Zhuhai, China 519041
}

\begin{abstract}
D printing technology is a substitution of traditional handcraft manufacturing, a renewal of traditional industry as well as a successful practice of introduction of IT. 3D printing has been widely used in many fields, this article analyzes main application fields and patterns of $3 \mathrm{D}$ printing, specifying the application of $3 \mathrm{D}$ printing in all fields, in the future, 3D printing must be an important tool for new product development of manufacturers.
\end{abstract}

\section{Keywords-3D printing; product design; application field}

\section{INTRODUCTION}

3D printing technology can shorten product R\&D period, reduce production costs, efficiently getting rid off the restriction of traditional process and enriching products' visual effect, which is called the most typical technology among the third industrial revolution, 3D printing technology has greatly promoted the development and research of all sciences and technologies.

3D printing technology has been widely used in many fields, the application objects of 3D printing can be any trade as long as the trade needs models and prototypes. For traditional product design field, the model making needs a long time, and it needs to undergo design, 3D modeling, material selection, spare parts making, assembly and so on, and the product designing companies need a great number of handmade model to test the design rationality and feasibility. For the hand-made models needs a long time, besides, the process is extremely complicated, so with a certain time, the production cost of hand-made model is higher, which causes the increase of production costs in enterprises. The introduction of $3 \mathrm{D}$ printing technology is huge revolution in the product design field, after more than 20-year development, it has been widely used in multiple product design and manufacturing fields.

\section{Auto DesigN}

In the product design field, auto manufacturing and design take the first to introduce 3D printing technology to produce auto model and entities, which can save costs for model making. KIA auto established a design center in California to produce concept car TELLURIDE, it is a SUV auto on the basis of 3D printing, during the production, and all parts such

*Project Source: Innovative Capability Cultivation Project of Zhuhai College Jilin University Research on Application of 3D Printing Technology in Product R\&D (Project No: 2016XJCQCX18). as door, steering wheel and dashboard adopt 3D printing technology, which is the first time for automaker KIA to adopt $3 \mathrm{D}$ printing technology to make key parts. It is a fearless attempt and a trend for concept car in the future.

In addition, the automaker giant Ford is the best one in the auto manufacturing through 3D printing technology, in early years, Ford adopted spare parts produced through 3D printing technology at autodrome, its main principle is, first of all, input the product design to computers, then adopt 3D printers to print before assembly, which is much more simple than traditional manufacturing process, besides, it needs no higher costs.

Ford attempted the 3D printing technology at Dearborn Research and Innovation Center, Michigan, America, in 2015, Ford adopted 3D printing technology to print Inlet Manifold for auto race and won finally; in addition, it also attempted to produce spare parts for autos through 3D printing technology, successful as well. During the production of electric vehicle Focus, a typical one, the high speed SLIP 3D print process of Carbon Inc was adopted to produce spare part-elastic grommet. Ford also attempted to adopt resin materials to produce spare parts for autos through 3D printing technology.

In the field of auto manufacturing, maybe 3D printing technology is inapplicable for production and manufacturing of large parts of autos, yet it may bring more economic benefits, meeting the requirements of clients who customize for special needs.

\section{FURNITURE DESIGN}

Traditionally moulds are adopted for furniture design in order to review the designed products, the introduction of $3 \mathrm{D}$ printing technology has changed the pattern of traditional furniture design, bringing a revolution of new materials and design.

Hungarian designer ollas gellert designed and produced "print to build" serial furniture supplies through 3D printers, the products have characteristics of low costs, strong sense of design, which break through traditional furniture design patterns, it can said to be an innovation in the furniture field, and the products he designed are a modularized furniture design. Rapid prototyping of 3D printing can realize the rapid production and making, which can save a lot of time, also providing different materials for selection. Design scheme is a personalized combination, it can be tables, cabinets and so on, diverse in form. The inspiration originated from connecting 
tools that children play with similar to LEGO, the materials used are plywood, $8 \mathrm{~mm}$ thick only, there are three angles optional for connection, that is $90 \mathrm{o}, 45 \mathrm{o}$ and $120 \mathrm{o}$, and users may exert what they can image and do artistically for free combination, enjoying the happiness in furniture assembly.

In addition, American Three-fifty Design Studio designer Yuriy Sklyar designed a software Tinkercad of 3D printing, which is excellent, and users may customize furniture products according to the needs and requirements of their own, besides, the whole product series are easy to install and assemble, some key parts are also designed with magnetic devices so as to make it easy for install and operate.

\section{JEWELRY DESIGN AND MAKING}

3D printing technology was very early used in the jewelry industry, generally during the making of wax mould, castable photosensitive resin or wax was used to print Jewelry wax mould, then it will be used to produce hold or silver through lost-wax casting.

Jewelry process belongs to precision manufacturing industry, because during the jewelry process and production, there are a lot of complete designs, which cause longer manufacturing time and higher costs, especially for the manufacturing of metal jewelry, previously the production period of stainless jewelry needed 15 days at least, besides, there are higher errors in manufacturing, which caused wastes of materials, time and costs.

Many jewelry providers attempt to print stainless accessories through metal 3D printers. Data statistics prove that printing stainless accessories through $3 \mathrm{D}$ printers can greatly improve the work efficiency and reduce the accessories production costs, the process procedures of stainless accessories are reduced to four processes from previous 14 ones, besides, the production and fineness are even better than that done traditionally.

\section{Clothing Design AND MAKING}

Making clothing through 3D printing technology can save time and costs, Cirque Du Soleil is well known around the world and the largest acrobats making team internationally, which has been exploring the application of 3D printing for over one year, recently the clothing that are made through $3 \mathrm{D}$ printing technology will be used for performance.

As for the clothing making, the strength of 3D print is to shorten the time to make clothing and accessories, because many of that are made by hand, which take a long time, needing more efforts, For example, to make an imperial crown needs about 60-70 hours by hand, with the 3D printing technology adopted, it just needs 16-18 hours, which greatly shortens the time to make.

In addition, the Circus has to perform frequently, so the clothing needs routine protection and maintenance which previously needed at least 8 hours per day, yet with the 3D printing technology adopted, as an innovative method, it has greatly shortened the protection and maintenance time, and eight hours are needed only to complete the clothing maintenance per quarter, thus a lot of time and costs are saved.

\section{SHOE MAKING}

During the traditional shoe making, from shoe design and mold making to material selection, molding and shoe production, it may need be repeated thousands times before making shoes meeting the thought of shoe designers. Ross Stevens, from University of Victoria, Wellington, instructed Earl Stewart to design and make XYZ shoe in 2013, which started the application of 3D printing technology in shoe making. The shoes made through 3D printing technology can be customized as required, which is kept accurate, basic data will be input the 3D printing equipment, select proper materials and print customized shoes, which are cozy and humanized. The innovation revolution in shoes has not only met consumers' individual needs but also realize the requirement on details by designers, showing the strength of 3D printing technology.

Prodways is a famous maker in 3D printing, and its product TPU material is an innovation for 3D printing. The material is easy to be processed and molded, which may produce the flexible parts of shoes and the products can be used for outsoles, innersoles and shoe pad. Its innovative materials make it be powerful competitor in traditional processing, and in addition, the breaking elongation of the TPU material exceeds $300 \%$, which can be used to make highly flexible shoe soles that are strong in fatigue resistance and saving costs in making. Meanwhile, Prodways also owns several patent technologies such as MOVINGLight Additive Manufacturing technology, and special 3D materials of its own can be used to make specially customized unique show sole designs. In addition, based on shoes making technologies, they have also developed a shoe sole made through 3D printing technology, the special making will scan users' vola to make shoe pads completely meeting requirements in size, based on the $3 \mathrm{D}$ printing technology, the shoe pads are more light and accurate in size, especially it is a good news for consumers who are troubled by plantar diseases. This year, Prodways cooperated with Nike, a giant sports provider, to produce top terminal gym shoes through its patent technology and TPU material.

Carbon Inc with its HQ at American Silicon Valley owns professional technology CLIP, famous in the trade, has cooperated with ADIDAS, a famous brand in clothing, and the CLIP technology is used to produce ADIDAS Futurecraft 4D gym shoes.

\section{TOY DESIGN AND MAKING}

Toy making will take a long time through traditional technique, and many start to produce toys through 3D printing technology. Mani Zamani, a toy design at Goteborg, Sweden, he attempted to produce doll models through 3D materials this year. From design to modified material selection and to final printing, the serial 3D printing model work took 3 months, and the materials used is a new 3D printing material made through SLS, that is selective laser sintering. The most important characteristics of the technique is directly burning metal products, besides, the technique for the metal burning is simple 
with higher precision, and the utilization rate of materials is far higher than that of traditional materials, the production period is shorter, saving materials and time. Mani Zamani products were popular after marketing and even collected by collectors.

With the development of 3D printing technology, materials and process, there will be more designers who turn to $3 \mathrm{D}$ printing toy making, and the making precision and process will become mature gradually in the future.

\section{CUSTOMIZED PRODUCTS}

The coming of 3D printing has pushed the development of customized products, Finnish Janne Kyttanen incorporated a $3 \mathrm{D}$ printing company which is a famous in making customized products. It introduced a customized platform Pix sweet last year, where clients may sign in and upload photos for 3D printing. The platform owns an ice-lolly material database, from which diverse lovely styles can be selected, and users may use the materials to customize ice-lolly mold and packaging so as to customize the products. There are many other individual companies like Janne Kyttanen, all of them provide customized products for clients such as mobile phone shell, individual pen, souvenir medals and so on, which enrich the people's life and keep it commemorative.

\section{OTHERS}

In recent years, 3D printing technology has been frequently used in aerospace, metal 3D printing especially metal laser printing is widely used in the field to make aircrafts or spare parts needed by aerospace such as titanium alloy parts, with the 3D printing technology widely applied and promoted in aerospace in the future, the metal laser $3 \mathrm{D}$ printing will be promising.

Within medical care and health care, especially the treatment and teaching of dentistry such as the making of dental crown and bridge, the 3D printing will save time and costs, which has been used widely in the field. In addition, in the medical field, 3D printing technology can be used to support operations, and medical simulation teaching is popularized gradually as well. On the European mold exhibition, the latest 3D hip joint inserts are shown, the product may provide customized resolution according to actual conditions of patients so as to complete the medical treatment, which is an innovation in material and method.

\section{CONCLUSION}

Though 3D printing technology is a newborn, yet it has been widely used in diverse fields, which has a bright future. The 3D printing technology can improve product precision in making, saving time, besides, efficient measures can be taken to lower the production costs, and it must be an important supporting tool for new product research and development of manufacturers in the future.

\section{REFERENCES}

[1] Wang Yungan, Wang Yi, 3D Printing Technology (3D Print, Printing World, Printing Future) [M]. Shanghai: Huazhong University of Science \& Technology Press, 2013.

[2] Yang Jiquan, Dai Ning, Hou Liya, 3D Print Design and Making [M].Beijing: Science Press, 2015.

[3] Wang Yungan, 3D Printing \& Free Form Fabrication [M]. Beijing: China Machine Press, 2012 